\author{
DaVid Fuentes ROMERO* \\ G UADALUPE ORTEGA VILLA** \\ Héctor VelázQuez G ONZÁlez***
}

\title{
POBLACIÓN PENAL EN FRONTERA: LA EXPRESIÓN DE UNA REALIDAD SOCIAL EN DESINTEGRACIÓN
}

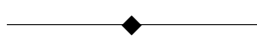

\section{RESUMEN}

Este trabajo tiene como objetivo presentar el perfil de los internos en el Cereso de Mexicali según lugar de nacimiento en relación con los delitos que motivaron su reclusión y con el consumo de drogas. Los datos utilizados provienen de las entrevistas realizadas a 928 reclusos (35.9\% de la población total del penal). Los resultados parecen indicar cierta especialización: los inmigrantes en delitos del fuero federal (asociados al narcotráfico y al tráfico de personas) y los nativos en aquellos del fuero común. También se observa un incremento en el consumo de drogas dentro del penal y un mayor consumo por parte de los nacidos en Baja California.

Palabras clave: Sistema penal, CERESOS (Centros de Rehabilitación Social), Frontera, Perfil criminal.

\section{ABSTRACT}

The objective of the present work is to show the profile of the inmates of the CERESO (Social Rehabilitation Center) in Mexicali, according to their birthplace, whit relation to the crimes which caused their convictions, and also whit their drug consumption. The data used come from interviews carried out among 928 prisoners, $35.9 \%$ of the total population of that penal institution. The results

\footnotetext{
* INVESTIGADOR DEL INSTITUTO DE INVESTIGACIONES SOCIALES DE LA UNIVERSIDAD AUTÓNOMA DE BAJA CALIFORNIA. BECARIO PROMEP. Correo electrónico: dfuentes@uabc.mx

**INVESTIGADORA DEL INSTITUTO DE INVESTIGACIONES SOCIALES DE LA UNIVERSIDAD AUTÓNOMA DE BAJA CALIFORNIA. BECARIO PROMEP. Correo electrónico: gortega@uabc.mX

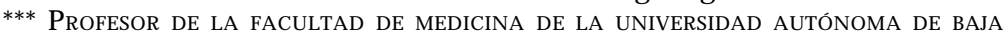
CALIFORNIA.
}

Artículo recibido en agosto de 2003.

Artículo aprobado en septiembre de 2003. 
Estudios Fronterizos, Nueva Época, vol. 4, núm. 7, enero-junio de 2003

seem to show a certain specialization: out of the state immigrants whit crimes of federal jurisdiction, connected to drug trafficking and humans beings traffic; and natives from Baja California with courts of equity crimes. An increase in drug consumption may be observed inside the prison, and much higher consumption by those born in Baja California.

Key words: Penal system, CERESOS (Social Rehabilitation Centers), Border, Criminal profile.

\section{INTRODUCCIÓN}

Mexicali, capital del estado de Baja California, es una ciudad que se ubica en la zona fronteriza que colinda con Estados Unidos. Estecentro poblacional seha convertido en una zona de paso para personas detodo el país, en su mayoría jóvenes, que desean llegar a Tijuana para encontrar trabajo o para cruzar la frontera e internarse en el vecino país del norte.

Buena parte de las personas que llegan a esta entidad lo hacen sin contar con recursos económicos para sobrevivir o para retornar a sus lugares de origen. En los medios masivos de comunicación -locales y nacional es-, reiteradamente se ha argumentado que la pobreza del país es la causa de la migración, y que Baja California se ha traducido en la muerte de buena cantidad de connacionales que intentan cruzar la frontera, ya sea por deshidratación, inanición o congelamiento, según sea la temporada del año. Pero además, en la sociedad bajacaliforniana existe la percepción de que los migrantes que no logran internarse en territorio estadounidensey permanecen en las ciudades fronterizas, son particularmente propensos a dedicarse a actividades ilícitas y, en consecuencia, a involucrarse en el tráfico de drogas, aunque no exista evidencia sólida que demuestre que esto es cierto.

También es conocido que en las ciudades de la frontera norte del país las actividades asociadas al narcotráfico se han desarroIlado rápidamente, no sólo por el hecho de ser puntos de llegada de droga para su posterior internación a Estados Unidos, sino porque en ellas la distribución y el consumo también han ido en aumento. En este sentido, de nuevo la percepción social es que el 
fenómeno se asocia a la pobreza y a la migración, aunque esto es difícil de probar, puesto que se trata de actividades clandestinas.

Una forma indirecta de aproximarnos al fenómeno dela delincuencia y sus posibles nexos con la migración es medianteel estudio de internos en los centros de readaptación social (cereso), puesto que son un reflejo del perfil delictivo de la sociedad a la que pertenecen - aunque hay que reconocer que evidentemente no están recluidas en los cereso todas las personas que delinquen-. En este sentido, el objetivo de este trabajo es presentar el perfil de Ios internos entrevistados en el Cereso de Mexicali en torno a dos temas: por un lado, los delitos que motivaron su reclusión, y por el otro, el consumo de drogas, diferenciando en el análisis a los reclusos según lugar de nacimiento.

Estetrabajo está organizado en dos apartados. En el primero se presenta un panorama general delos reclusorios del país, quesirve de referente para contextualizar al Cereso de Mexicali en el sistema penitenciario nacional; mientras que en el segundo se reportan los resultados de las entrevistas, especialmente aquellos relacionados con el perfil sociodemográfico de los internos, los delitos cometidos y el consumo de drogas.

Los datos aquí presentados son resultado delas entrevistas realizadas a 35.9\% de los reclusos (928, de un total de 2583 internos a principios de 2001). El levantamiento de información inició en junio del año 2000 y finalizó en abril de 2001. Para ello se utilizó un cuestionario estructurado, y para la realización de dicha actividad se dispuso de permiso para ingresar al reclusorio dos veces a la semana, de aquí que la recopilación de información fuelenta y difícil. Asimismo, cabemencionar que no fue posibleaplicar un muestreo probabilístico - aunque el tamaño de la muestra fue lo suficientemente grande para ello- por dos razones: primera, porque no se dispuso del marco muestral para tal fin (esto es, no se tuvo acceso al listado de los reclusos para hacer la selección al eatoria de los internos a entrevistar); y segunda, porqueal inicio del levantamiento los internos mostraron desconfianza, de aquí que primero se efectuó una labor de sensibilización y sólo se 
Estudios Fronterizos, Nueva Época, vol. 4, núm. 7, enero-junio de 2003

entrevistaron los reos que voluntariamente acudieron a responder el cuestionario. ${ }^{1}$

Si bien la información en torno a la población interna en los ceresos del país no es muy abundante, a continuación se presenta un contexto general delos centros penitenciarios y desusinternos en nuestro país.

\section{El Ámbito carcelario en México}

Uno de los graves problemas que sufre la mayoría de las prisiones mexicanas es la sobrepoblación, además de carecer de instalaciones adecuadas, equipo necesario y falta de condiciones dignas para la rehabilitación. Los ceresos tampoco brindan a los reos opciones de trabajo, y las actividades educativas, deportivas o recreativas son nulas o muy escasas. De igual forma, se advierte que en al gunos centros del país son los familiares quienes proporcionan alimentación y vestido a los presos, porque los centros de rehabilitación no se responsabilizan de satisfacer estas necesidades.

En nuestro país, la operación del aparato penitenciario ha girado en torno a la extorsión institucionalizada; esto es, a la extracción sistemática de recursos económicos del interno y de sus visitantes, lo que privilegia la violación de los derechos humanos y del derecho penitenciario escrito. Al reo se le impone un modo de vida que tiende a aislarlo del mundo exterior, a quebrantar su personalidad y a envilecerlo, al ser sometido a una serie de vejaciones, al reducir su capacidad de trabajo obligándolo al ocio forzoso, y al exponerlo al hacinamiento, hambre, angustias y depresiones quelo conducen a la pérdida de sociabilidad y al consumo de drogas dentro de las instalaciones del cereso.

${ }^{1}$ Los reclusos encuestados que acudieron voluntariamente a ser entrevistados lo hicieron porque sólo a ellos se les tomaron muestras de sangre para detectar la presencia del virus de inmunodeficiencia adquirida $(\mathrm{VIH})$ y de hepatitis $\mathrm{C}$, que fue uno de los objetivos del proyecto, cuyos resultados aún no se publican. 
A causa de la manera como operan los ceresos, éstos se han convertido en instituciones generadoras de un marcado odio hacia las autoridades, de rencores hacia su comunidad, y representan, en sentido estricto, un facto al tamentecriminógeno (Huacuja, 1989).

La situación descrita no se presenta sólo en al gunos cereso en particular, sino que es un fenómeno social de dimensiones nacionales, validada por organismos internacionales que han difundido ampliamente el problema. Así, "desde cualquier punto de referencia, las condiciones de los penales mexicanos están por debajo de los niveles mínimamente aceptables de dignidad humana. En prácticamente todos los penales visitados, Ios internos están recluidos en dormitorios sucios, insalubres y sobrepoblados" (Americas Watch, 1991:127).

En relación con la sobrepoblación carcelaria, en el Programa de Prevención y Readaptación Social 1995-2000 (1996) se menciona que, a diciembre de 1995 esta era de 2026 internos en 155 centros de reclusión, así como también sealudea las seis entidades federativas con los centros penitenciarios con mayor sobrepoblación en el país: N ayarit, Baja California, Colima, N uevo León, Chihuahua y Sonora. De dicha información destaca, por un lado, que en 1995 la sobrepoblación carcelaria en México era mucho mayor a los 2026 internos, pues tan sólo en las seis entidades federativas mencionadas la población excedenteera de 5632 internosy, por el otro, quedeesas seis entidades cuatro se ubican en la frontera norte del país, de las cuales Baja California ocupa el segundo lugar a nivel nacional y el primero entrelos estados fronterizos (ver cuadro 1).

Los datos de 1998 muestran que la sobrepoblación carcelaria aumentó rápidamente entre los años 1995 y 1998, pues en ese periodo la población excedente en los centros carcelarios de las seis entidades con mayor sobrepoblación pasó de 37.7\% a 91.7\% (ver cuadro 1). Además, resalta que en 1998 hubo un cambio en las entidades con mayor problema, pues aparece en primer lugar el Distrito Federal, que hace queN ayarit y Baja Cal ifornia se desplacen al segundo y tercer lugar, respectivamente, pero no porque haya disminuido la sobrepoblación en dichas entidades. 
Estudios Fronterizos, Nueva época, vol. 4, núm. 7, enero-junio de 2003

CUADRO 1. Entidades federativas con los centros penitenciarios con mayor sobrepoblación en el país. Diciembre de 1995 y diciembre de 1998.

\begin{tabular}{|c|c|c|c|c|c|}
\hline $\begin{array}{c}\text { Entidad } \\
\text { federativa }\end{array}$ & $\begin{array}{l}\text { N úmero } \\
\text { de centros }\end{array}$ & Capacidad & Población & $\begin{array}{l}\text { Sobrepobl } \\
\text { A bsoluta }\end{array}$ & $\begin{array}{c}\text { Iación } \\
\%\end{array}$ \\
\hline $\begin{array}{l}\text { Total en } 1995 \\
\text { Nayarit } \\
\text { Baja California } \\
\text { Colima } \\
\text { Nuevo León } \\
\text { Chihuahua } \\
\text { Sonora }\end{array}$ & $\begin{array}{r}68 \\
20 \\
4 \\
3 \\
13 \\
14 \\
14\end{array}$ & $\begin{array}{r}14940 \\
1192 \\
3630 \\
876 \\
3268 \\
2202 \\
3772\end{array}$ & $\begin{array}{r}20572 \\
2275 \\
5105 \\
1187 \\
4337 \\
2844 \\
4824\end{array}$ & $\begin{array}{r}5632 \\
1083 \\
1475 \\
311 \\
1069 \\
642 \\
1052\end{array}$ & $\begin{array}{l}37.7 \\
90.9 \\
40.6 \\
35.5 \\
32.7 \\
29.2 \\
27.9\end{array}$ \\
\hline $\begin{array}{l}\text { Total en } 1998 \\
\text { Distrito Federal } \\
\text { Nayarit } \\
\text { Baja California } \\
\text { Coahuila } \\
\text { Colima } \\
\text { Chiapas }\end{array}$ & $\begin{array}{r}67 \\
8 \\
20 \\
4 \\
9 \\
3 \\
23\end{array}$ & $\begin{array}{r}18037 \\
7590 \\
1119 \\
3812 \\
1994 \\
954 \\
2568\end{array}$ & $\begin{array}{r}34581 \\
16623 \\
2380 \\
7108 \\
3230 \\
1155 \\
4085\end{array}$ & $\begin{array}{r}16544 \\
9033 \\
1261 \\
3296 \\
1236 \\
201 \\
1517\end{array}$ & $\begin{array}{r}91.7 \\
119.0 \\
112.7 \\
86.5 \\
62.0 \\
21.1 \\
59.1\end{array}$ \\
\hline
\end{tabular}

Fuentes: Para 1995: “Programa de Prevención y Readaptación Social 1995-2000”. Diario 0 ficial de la Federación, 19 de julio de 1996, cuadro 2, p. 13 (excepto las dos últimas columnas, que son elaboración propia).

Para 1998: Secretaría de Gobernación. Subsecretaría de Protección Civil, Prevención y Readaptación Social. Dirección General de Prevención y Readaptación Social 1998. Reporte interno (mimeo).

En realidad, tanto en 1995 como en 1998, en Baja California sólo operaban 3 cereso, el cuarto (ubicado en El Hongo, municipio de Tecate) inició operaciones el 20 de agosto del 2002, aunque ya en 1998 estaba construido (ver A legre, 2002).

La información del Instituto Nacional deEstadística, Geografía elnformática (INEGI) confirma que la sobrepoblación carcelaria ha ido en aumento en nuestro país. A pesar deque los espacios disponibles se incrementaron $77.9 \%$ en el periodo de 1990 a 1999, el promedio de ocupantes por centro penitenciario, lejos de disminuir, aumentó $52.3 \%$, ya que de un promedio de 209.7 internos por centro en 1990, pasó a 319.5 en 1999 (ver cuadro 2). Además, los datos indican queel peso relativo delos recluidos por haber cometido un delito federal disminuyó, al pasar de $36.3 \%$ en 1990 , a $26 \%$ en 1999, aunqueen ambos casos el número de internos aumentó (ver cuadro 2).

En México, y en otros países latinoamericanos, se presenta un fenómeno penitenciario ignominioso: en las cárceles se aglomeran 
CUADRO 2. Indicadores de los centros penitenciarios en México, 1990 y 1999.

\begin{tabular}{|lrrrr|}
\hline \multicolumn{1}{|c}{ Indicador } & \multicolumn{2}{c}{ Año } & \multicolumn{3}{c|}{ Incremento } \\
& $\mathbf{1 9 9 0}$ & $\mathbf{1 9 9 9}$ & A bsoluto & \multicolumn{1}{c|}{$\%$} \\
\hline Centros penitenciarios & 444 & 447 & 3 & 0.7 \\
Espacios disponibles & 61173 & 108808 & 47635 & 77.9 \\
Población penitenciaria total & 93119 & 142800 & 49681 & 53.4 \\
Promedio de ocupantes por centro & 209.7 & 319.5 & 110 & 52.3 \\
Pob. penitenciaria del fuero federal & 33779 & 37119 & 3340 & 9.9 \\
Pob. penitenciaria del fuero común & 59340 & 105681 & 46341 & 78.1 \\
& & & & \\
Pob. penitenciaria fuero fed. (\%) & $36.3 \%$ & $26.0 \%$ & & \\
Pob. penitenciaria fuero común (\%) & $63.7 \%$ & $74.0 \%$ & & \\
\multicolumn{1}{c}{$\quad$ Total } & $100.0 \%$ & $100.0 \%$ & & \\
\hline
\end{tabular}

Es igual a la población penitencia total/ total centros.

FuENTE: Los datos absolutos se obtuvieron del: A nuario estadístico. Estados U nidos M exicanos, edición 2000. INEGI, Ags., 2001, cuadro 8.6, p. 175. Los cálculos son elaboración propia.

indistintamente procesad os y sentenciados. Estereotipados con el estigma social de ser delincuentes, todos los que allí llegan son despojados de su individualidad y vida privada para ser sujetos de las reglas no escritas de la cárcel. A ntes de probar mediante un proceso judicial la culpabilidad del presunto infractor dela ley, se le castiga con la pérdida dela libertad y la disminución del prestigio social. De esta manera, la duración extraordinaria de los procesos penal es provoca una distorsión que da como resultado que el auto de prisión preventiva (de formal prisión) se convierta en sentencia (Zaffaroni, 1999).

Los presos sin condena permanecen en prisión durantelargos periodos que exceden en mucho los límites marcados por la C onstitución. Así, las cárceles en México están sobrepobladas, en gran parte, por la ineficiencia en la impartición de justicia.

Como medida cautelar o precautoria que establecen la Constitución y el Código Penal, la prisión preventiva ha sido objeto de serias reflexiones por parte de los especialistas en derecho penal. Los organismos defensores de los derechos humanos han hecho severas críticas a su aplicación, la Comisión Nacional de Derechos Humanosal respecto señala: “En nuestro país, más dela mitad de los internos son presos sin condena. Sin duda, no hay prisión 
más injusta quela preventiva, pues se cumplesin previa condena judicial" (Barreda, 1991:13).

Otro de los graves problemas de la mayoría de los centros penitenciarios del país es la falta depersonal especializado para brindar atención y tratamiento adecuado a los internos (v. gr. custodios, psicólogos, médicos, odontólogos, entre otros), ya que $22 \%$ delos cereso no tiene suficiente personal técnico, administrativo y de custodia. En esterubro Baja California ocupa el primer lugar (ver cuadro 3).

CUADRO 3. Número de internos por tipo de personal. Diciembrede 1995.

\begin{tabular}{|lcc|}
\hline Entidad federativa & Internos por custodio & Internos por técnico \\
\hline Baja California & 27.44 & 221.95 \\
Sonora & 9.53 & 151.06 \\
Veracruz & 25.91 & 56.38 \\
Distrito Federal & 3.30 & 13.13 \\
Estado de México & 2.90 & 12.56 \\
\hline
\end{tabular}

FuENTE: Secretaría de Gobernación. Subsecretaría de Protección Civil, Prevención y Readaptación Social. Dirección General de Prevención y Readaptación Social, 1998. Reporte interno (mimeo).

En México, el personal penitenciario no goza de estabilidad laboral y la remuneración económica, cuando existe, es muy baja. A demás, el sistema penitenciario tiene un rezago en la capacitación del personal, ya que en 1995, de los 30000 servidores públicos registrados, sólo recibieron capacitación 8 477, lo que ha incidido negativamenteen la calidad delos servicios (Secretaría de Gobernación, 1998).

Si bien la mayoría de los reclusorios cuenta con servicio deenfermería para primeros auxilios, estos carecen de instrumental y de medicamentos básicos, y es una excepción la atención dental, aunque para la atención de los presos considerados como graves, existen acuerdos con los hospital es de la Secretaría de Salud.

En el caso particular de Baja Cal ifornia la situación no es muy diferente dela del resto del país. La población en las cárcel es seha triplicado en los últimos diez años. La sobrepoblación y el poco 
personal son el común denominador del sistema correccional. Si bien en el estado existen cuatro cereso en funcionamiento - uno en Tijuana, uno en Mexicali, otro en Ensenada y el cuarto en El Hongo, municipio de Tecate²-, todavía a principios de 2002 sólo funcionaban tres, que en conjunto tenían una capacidad para albergar a aproximadamente 4411 personas pero al ojaban a 12620 internos (Jiménez Vega, 2002:3A).

Los datos disponibles para el año de 1998 indican que los residentes de Baja California presentan una propensión a delinquir a una edad menor que el resto del país. Del total de presuntos delincuentes registrados en los juzgados del fuero común en el país, $79.4 \%$ deellos era menor de 40 años de edad, mientras que en Baja California ese porcentaje resultó de 84.7\% (INEGI, 2000).

Los porcentajes delos del incuentes sentenciados por delitos del fuero común guardan una distribución semejante a la anterior, pues a nivel nacional $81.2 \%$ del total de sentenciados era menor de 40 años, mientras que en Baja California la proporción fue de $85.4 \%$. En los delitos del fuero federal sucedelo mismo, ya queen Baja California un poco más de $80 \%$, tanto en presuntos delincuentes como de delincuentes sentenciados, se concentra en los grupos de 39 o menos años de edad, mientras que los porcentajes para el conjunto del país no llegan a 77\% (INEGI, 2000).

Otro aspecto quellama la atención en las fuentes disponibles es el alto índice de delincuencia en la entidad. En el año 2000 Baja California aportaba $2.6 \%$ de la población total del país (INEGI, 2001b), pero en 1998 concentró a 4.5\% de los presuntos delincuentes y a $5.5 \%$ de los sentenciados del fuero común a nivel nacional, porcentajes al rededor del doble del peso relativo de la población.

\footnotetext{
2 El cereso de El Hongo fue puesto en funcionamiento el 20 de agosto de 2002. Inició operaciones para desahogar la sobrepoblación del Cereso de Tijuana, con el traslado de aproximadamente 2000 reos provenientes de ese centro penitenciario (conocido como "El Pueblito"). Sin embargo, a la fecha (fines de agosto de 2002) no se prevé que internos del Cereso de Mexicali sean reubicados en ese nuevo centro.
} 
Estudios Fronterizos, Nueva Época, vol. 4, núm. 7, enero-junio de 2003

En los delitos del fuero federal la situación es más grave, puesto queen esemismo año, Baja Cal ifornia aportó 9.3\% delos presuntos delincuentes y 8\% delos delincuentes sentenciados del país (INEGI, 2001a).

Delos delitos del fuero federal cometidos en Baja Cal ifornia en 1998, sobresalen dos por su importancia en el total nacional: en primer lugar están los relacionados con el tráfico de personas (35.5\% del total de sentenciados y $36.4 \%$ de los presuntos delincuentes, ambos en relación con el país); el segundo lugar corresponde a delitos contra la salud, con $9.4 \%$ de los delincuentes registrados a nivel nacional y $8.4 \%$ de los sentenciados (INEGI, 2001a).

El panorama hasta aquí expuesto sirve como marco dereferencia del perfil dela población interna en el Cereso de M exicali. Los datos que a continuación se presentan sólo corresponden a los 928 internos que formaron parte de la muestra.

\section{Los internos en el CERESO de MexicAlI}

El cereso dela ciudad de Mexicali tiene una capacidad para alojar al rededor de 1850 internos; sin embargo, actualmente cuenta con una población querebasa los cuatro mil reclusos, ${ }^{3}$ lo que significa un sobrepoblamiento superior al $100 \%$. Además de la sobrepoblación - queevidentementeimplica hacinamiento-, estecentro comparte muchos de los problemas que presentan los demás Cereso del país: rezago judicial, consumo de drogas, falta de actividades querealmentetiendan a evitar quelos internos vuelvan a delinquir, convivencia de reos peligrosos con aquel los que cometieron delitos menores.

En la visitas realizadas al cereso, sepudo advertir queen él operan grupos de poder entre los internos que las diferentes administraciones del penal han utilizado para sus propósitos particulares.

\footnotetext{
${ }^{3}$ A finales de julio de 2002, había más de cuatro mil internos en el Cereso de Mexicali (comunicación personal proporcionada por personal de la Secretaría Estatal de Seguridad Pública de Baja California, agosto de 2002).
} 
La venta de todo tipo de estupefacientes es una actividad en la que participan por igual internosy personal del reclusorio. Los programas existentes en materia de rehabilitación defármaco-dependientes ha tenido un mínimo impacto en los internos.

Por otro lado, entre los reclusos existe una estructura pirática de poder, un liderazgo delimitado por el cártel carcelario, que re produce la violencia como forma habitual de vida y que puede tener diversas manifestaciones como la autoflagelación (cortes en el cuello, cicatrices en lugares específicos) o el uso detatuajes como expresión de pertenencia a grupos o subgrupos de la sociedad carcelaria que constituyen barreras infranqueables y que, sin embargo, deben convivir juntos.

La población interna muestra un profundo desprecio hacia quienes gozan de ciertas consideraciones o quienes son de reciente reclusión, lo que se expresa en agresiones físicas - que pueden ser arregladas con los puños e incluso llegar al extremo dela violación sexual.

Las instalaciones son insalubres, los servicios sanitarios inadecuados, de aquí quela falta deaseo personal es el común denominador de los internos. Las instalaciones dela cocina y consultorio médico tampoco son adecuadas, y el alimento que reciben es escaso y de poca calidad.

Con el fin decaracterizar alos internos entrevistados del Cereso de Mexicali, la información que se presenta a continuación se organizó en tres secciones: 1) demográfica, 2) delitos cometidos y rezago judicial , y 3) consumo de drogas. En la mayoría de ellos se hace alusión al lugar de nacimiento de los internos.

\section{a) Características de los internos entrevistados}

El perfil delos internos que en el año 2000 se encontraban recluidos en el Cereso de M exicali concuerda con los datos presentados en materia de del itos en el apartado anterior. Son mayoritariamente jóvenes en edad productiva; alrededor de dos terceras partes (67.1\%) de ellos tienen 34 o menos años de edad, mientras que $84.2 \%$ es menor de 40 años. Sin embargo, los reclusos nacidos en 
Estudios Fronterizos, Nueva Época, vol. 4, núm. 7, enero-junio de 2003

la entidad tienen un promedio de edad significativamentemenor al de aquellos nacidos en otro estado del país (29.3 y 32.3 años de edad respectivamente 4 ). A proximadamente nueve de cada diez presos son varones (93.2\%), y el grupo de edad más frecuente, tanto en hombres como en mujeres, es el de los 25 a 29 años.

Otro aspecto a destacar es el predominio de la población no nacida en Baja California (55.1\%), con un predominio de los nacidos en otra entidad del país (54\%), porcentaje que resulta el evado porque la información censal del año 2000 reporta que los no nacidos en el estado eran el $43.6 \%$ dela población total dela entidad (incluidos los extranjeros), y más aún porque en el municipio de Mexicali ese porcentaje es de 33.4\% (INEGI, 2001b).

De igual manera, Ilama la atención el el evado peso que en el grupo delas mujeres tienen las nacidas en otra entidad federativa $(62.9 \%)$, puesto que era de esperar una proporción semejante al porcentaje del total de internos (es decir, 54.0\%; ver cuadro 4). Cabemencionar que del total dereos no nacidos en Baja California, $30.5 \%$ son originarios de Sinaloa, seguidos en orden de importancia por los nacidos en Sonora (19.5\%) y en Jalisco (9.5\%).

Los bajos niveles educativos y de capacitación son características que general mente se relacionan con al tos niveles de delincuencia; ello quizá se deba a quela escasa formación escolar a su vez se asocia con la pobreza (Programa de Prevención..., 1996). En el caso del cereso de M exicali esto no sucede, pues seobserva queel peso de los internos sin estudios es muy bajo. Menos de uno de cada cien reclusos nacidos en Baja California no cursaron estudios de ningún tipo $(0.7 \%)$, mientras que en los nacidos en otra entidad son un poco más de dos de cada cien (2.2\%); en conjunto, sólo 2.6\% de los internos no había asistido a la escuela. En estesentido, cabe destacar que el censo de población del año 2000 reporta que 6.3\% de la población de 15 y más años de edad residente en esta entidad federativa no había recibido instrucción alguna (INEGI,

${ }^{4} \mathrm{Si}$ bien la muestra no obedecea un diseño probabilístico, la prueba para comparar las medias indicó que son significativamente diferentes $(p<.001)$. 
CUADRO 4. Internos en el cereso según lugar denacimiento y según sexo.

\begin{tabular}{|lccc|}
\hline \multicolumn{1}{|c}{ Lugar de nacimiento } & \multicolumn{2}{c}{ Sexo } & Total \\
& M ujer & H ombre & \\
\hline Total & 62 & 866 & 928 \\
Baja California & 22 & 392 & 414 \\
En otro estado & 39 & 462 & 501 \\
En otro país & 1 & 9 & 10 \\
No respondió & & 3 & 3 \\
& & & \\
Sexo según lugar de nacimiento (porcentajes) & 100 & 100 & 100 \\
Total & 35.5 & 45.3 & 44.6 \\
Baja California & 62.9 & 53.3 & 54.0 \\
En otro estado & 1.6 & 1.0 & 1.1 \\
En otro país & 0.0 & 0.3 & 0.3 \\
No respondió & & \\
\hline
\end{tabular}

FUENTE: Resultados del proyecto "Factores de riesgo asociados a enfermedades de transmisión sexual y por sangre en un cereso". Instituto de Investigaciones Sociales de la UABC, 2000-2001.

2001b), de aquí que resulte muy bajo el porcentaje de reclusos sin instrucción en relación con el total poblacional.

Al comparar la escolaridad según el lugar de nacimiento, se observa un perfil muy semejante, sin embargo, los internos nacidos en Baja California presentan un porcentajeligeramente superior en educación básica (79.5\%) queel resto (75\%), particularmente los que tienen estudios de secundaria ( $47.8 \%$ de los nacidos en la entidad frente a $35.1 \%$ de los nacidos en otro estado).

En cuanto a los internos con estudios superiores a la educación obligatoria, el porcentaje de los nativos de Baja California es casi igual al de los que provienen de otra entidad del país (18.1\% y $18.4 \%$, respectivamente). No obstante, el porcentaje de internos con estudios universitarios es superior en los migrantes queen los originarios de Baja California (3.6\% y $1.2 \%$, respectivamente).

Final mente, cabe mencionar que más de la mitad de los internos (58.9\%) tienen de dos a menos de cinco años recluidos; en conjunto, quienes tienen menos decinco años suman $88.5 \%$ delos reclusos. Por otro lado, para $73.7 \%$ de los entrevistados es su primer ingreso a un penal, mi entras que el $6.6 \%$ cuenta con cinco o más internaciones. 
Si bien en general más de la mitad de los entrevistados están internados por la comisión de delitos del fuero común (53.8\%), el peso relativo de los del fuero federal es elevado (42.1\%), sobre todo si se considera que a nivel nacional el porcentaje por este último tipo de delitos fue de $26 \%$ en 1999 (ver cuadros 2 y 5). Un dato que llama la atención en el grupo de las mujeres es que la comisión de delitos federales no sólo es más frecuente que en los hombres ( $54.8 \%$ y $41.2 \%$, respectivamente), sino que también tiene un mayor peso relativo quelos del fuero común (ver cuadro 5).

Cabe mencionar queel delito que presenta la mayor frecuencia entre los presos entrevistados, independientemente del fuero de que se trate, es de carácter federal, y corresponde a delitos contra la salud, es decir, a la posesión, transportación o venta de drogas (34.5\% del total y $80.8 \%$ de los del fuero federal ), mientras que el robo ocupa el segundo lugar en el conjunto (29.9\%) y el primero dentro delos del fuero común. Ello indica la importancia que tieneel tráfico dedrogas en la comisión dedel itos, así como también muestra que es una actividad que está enraizada en la sociedad bajacaliforniana.

CUADRO 5. Internos según sexo y ámbito del delito cometido.

\begin{tabular}{|c|c|c|c|c|c|}
\hline Sexo & Fuero común & Fuero federal & $\begin{array}{l}\text { Común } \\
\text { y federal }\end{array}$ & No respondió & Total \\
\hline Total & 499 & 391 & 20 & 18 & 928 \\
\hline Mujer & 27 & 34 & & 1 & 62 \\
\hline Hombre & 472 & 357 & 20 & 17 & 866 \\
\hline \multicolumn{6}{|c|}{ Sexo según tipo de delito (\%) } \\
\hline Total & 53.8 & 42.1 & 2.2 & 1.9 & 100 \\
\hline Mujer & 43.5 & 54.8 & & 1.6 & 100 \\
\hline Hombre & 54.5 & 41.2 & 2.3 & 2.0 & 100 \\
\hline \multicolumn{6}{|c|}{ Tipo de delito según sexo (\%) } \\
\hline Total & 100 & 100 & 100 & 100 & 100 \\
\hline Mujer & 5.4 & 8.7 & & 5.6 & 6.7 \\
\hline Hombre & 94.6 & 91.3 & 100 & 94.4 & 93.3 \\
\hline
\end{tabular}

FuENTE: Resultados del proyecto "Factores de riesgo asociados a enfermedades de transmisión sexual y por sangre en un cereso". Instituto de Investigaciones Sociales de la UABC, 2000-2001. 
Los datos del cuadro 6 permiten advertir al gunas diferencias en la comisión de del itos entrelos internos nacidos en Baja Cal ifornia y los nacidos en otra entidad del país. En primer lugar se observa que los originarios de Baja California cometieron delitos mayoritariamentedel fuero común, mientras quelos delitosfederales son más frecuentes en los nacidos en otro estado. En segundo lugar, seobserva quela distribución delosinternos por lugar denacimiento y delito cometido (sección A del cuadro 6) muestra una mayor presencia derobosy asal tos en los nativos (70.8\%), mientras queel homi cidio y el secuestro son más frecuentes en los no nativos; sin embargo, hay quereconocer queal analizar la distribución a nivel de delito según lugar de nacimiento (ver sección B del cuadro 6), resulta que un poco más de la mitad del total de los homicidios fueron cometidos por nativos de la entidad. También destaca en esa sección del cuadro 6 que si bien en términos relativos el secuestro no es un delito frecuente(3.1\% delos del fuero común, es decir 16 secuestros), tres de cada cuatro fueron cometidos por no nativos.

En materia de delitos del fuero federal es evidente que aqueIlos asociados al narcotráfico tienen mayor peso en todas las distribuciones de los lugares de nacimiento (sección C del cuadro 6); de igual forma llama la atención queel tráfico deindocumentados es muy poco frecuente en los nacidos en Baja Cal ifornia, pues 8.4 de cada 10 internos que cometieron este delito son originarios de otra entidad del país.

En relación con los internos nacidos en otro estado del país según su tiempo deresidencia en Baja Cal ifornia (cuadro 7), destaca el hecho de que más de la mitad (62\%) de internos migrantes tenían cinco años o menos de residir en la entidad cuando ingresaron al cereso, es decir, son migrantes relativamente recientes.

De igual forma, en el grupo de migrantes recientes se concentra $72.7 \%$ detodos los internos no nativos detenidos por secuestro, así como $76.4 \%$ por delitos contra la salud y $81.3 \%$ por tráfico de indocumentados. Es decir, hay un cambio en la comisión dedelitos por partedelos migrantes en función desu tiempo deresidencia en Baja California, pues aquellos que tenían cinco o menos años en la 
Estudios Fronterizos, Nueva época, vol. 4, núm. 7, enero-junio de 2003

CUADRO 6. Internos entrevistados según lugar de nacimiento y principal delito cometido.*

\begin{tabular}{|c|c|c|c|c|c|}
\hline $\begin{array}{l}\text { Principal delito cometido } \\
\text { Según fuero }\end{array}$ & \multicolumn{2}{|c|}{$\begin{array}{r}\text { N acid } \\
\text { Baja Cfa. Otro edo. }\end{array}$} & $\begin{array}{l}\text { o en } \\
\text { Otro país }\end{array}$ & No resp. & Total \\
\hline Total internos (absolutos) & 414 & 501 & 10 & 3 & 928 \\
\hline Del fuero común & 295 & 210 & 3 & 2 & 510 \\
\hline Del fuero federal & 107 & 285 & 7 & 1 & 400 \\
\hline No respondió & 12 & 6 & & & 18 \\
\hline \multicolumn{6}{|l|}{ Fuero común (\%) } \\
\hline A. Lugar de nac. según delitos & 100.0 & 100.0 & 100.0 & 100.0 & 100.0 \\
\hline A salto & 5.1 & 3.3 & & & 4.3 \\
\hline Homicidio & 9.8 & 12.9 & & & 11.0 \\
\hline Robo & 70.8 & 61.0 & 66.7 & & 66.5 \\
\hline Secuestro & 1.4 & 5.2 & 33.3 & & 3.1 \\
\hline Otros delitos & 12.9 & 17.6 & & 100.0 & 15.1 \\
\hline B. D elito según lugar de nac. & 57.8 & 41.2 & 0.6 & 0.4 & 100.0 \\
\hline A salto & 68.2 & 31.8 & & & 100.0 \\
\hline Homicidio & 51.8 & 48.2 & & & 100.0 \\
\hline Robo & 61.7 & 37.8 & 0.6 & & 100.0 \\
\hline Secuestro & 25.0 & 68.8 & 6.3 & & 100.0 \\
\hline Otros delitos & 49.4 & 48.1 & & 2.6 & 100.0 \\
\hline \multicolumn{6}{|l|}{ Fuero federal (\%) } \\
\hline C. Lugar de nac. según delitos & 100.0 & 100.0 & 100.0 & 100.0 & 100.0 \\
\hline Contra la salud & 82.2 & 80.4 & 71.4 & 100.0 & 80.8 \\
\hline Tráfico de indocumentados & 4.7 & 11.6 & 14.3 & & 9.8 \\
\hline Otro delito & 13.1 & 8.1 & 14.3 & & 9.5 \\
\hline D. D elito según lugar de nac. & 26.8 & 71.3 & 1.8 & 0.3 & 100.0 \\
\hline Contra la salud & 27.2 & 70.9 & 1.5 & 0.3 & 100.0 \\
\hline Tráfico de indocumentados & 12.8 & 84.6 & 2.6 & & 100.0 \\
\hline Otro delito & 36.8 & 60.5 & 2.6 & & 100.0 \\
\hline
\end{tabular}

* Los totales en número de internos del fuero común y federal (510 y 400, respectivamente) no coinciden con los del cuadro 5 (499 y 391) porque hay 20 internos que cometieron delitos de ambos fueros, en cuyo caso se clasificaron en aquel de mayor gravedad en términos de sentencias.

Fuente: Resultados del proyecto "Factores de riesgo asociados a enfermedades de transmisión sexual y por sangre en un cereso". Instituto de Investigaciones Sociales de la UABC, 2000-2001. 
entidad integran el único grupo en el que la comisión de delitos federales supera a los del fuero común (ver sección B del cuadro 7).

En términos de rezago judicial, aunque constitucionalmente se establece que la prisión preventiva no debe exceder de un año, contado a partir de la declaración de competencia por parte del juez correspondiente (Constitución Política de los Estados U nidos M exicanos, art. 20, fracc. VIII), es sabido que en México hay un rezago judicial del $70 \%$ (Programa dePrevención y Readaptación Social 1995-2000). Sin embargo, si bien en el caso de los internos en el cereso deM exicali también sepresenta esta situación, ella no alcanza los niveles observados en el conjunto del país. A un así, el cuadro 8 muestra queel problema es importante, ya que $40.6 \%$ de los internos con más de un año en el Cereso — pero sin llegar a los dos años- todavía no conocían su sentencia; de ellos el mayor rezago seobserva en los internos que cometieron delitos del fuero común (50\%), y de estos en los homicidas se concentra el mayor problema, puesto que ninguno había sido sentenciado, mientras queel rezago en las sentencias de los delincuentes del fuero federal, en términos relativos, representa casi la mitad (27.2\%) de los del fuero común.

Como es de esperar, conforme aumenta el tiempo en el cereso es menor el rezago observado; no obstante, existen al gunos casos extremos de internos que han permanecido en el penal entre tres y cinco años y aún no han recibido sentencia (ver cuadro 8).

\section{c) A dicciones}

Otro tema conocido en México es el consumo de drogas en el interior de los cereso; muestra de ello es quea los pocos días de haber sido desmantel ada la red de distribución en la cárcel de Tijuana, había varios presos con problemas de salud por el síndrome de abstinencia, y se calculaba que al rededor de 70\% de los internos consumía drogas (Cornejo, 2002). En el caso del Cereso de Mexicali, seis de cada diez internos entrevistados consumen al gún tipo de droga, y de el los al rededor de $40 \%$ consumen más de una. Al respecto, seobservaron diferencias entre los nativos en Baja California 
CUADRO 7. Internos nacidos en otro estado según años de residencia en Baja California y delito cometido. Porcentajes.

\begin{tabular}{|c|c|c|c|c|c|}
\hline D elito cometido & \multicolumn{4}{|c|}{ Años de residir en M exicali } & $\begin{array}{c}\text { Total } \\
\text { migrantes }\end{array}$ \\
\hline \multicolumn{6}{|c|}{ A. Delito por años de residencia } \\
\hline Total & 62.7 & 13.6 & 8.2 & 15.5 & 100.0 \\
\hline Fuero común & 46.9 & 19.6 & 14.4 & 19.1 & 100.0 \\
\hline A salto & 28.6 & 42.9 & 14.3 & 14.3 & 100.0 \\
\hline Homicidio & 25.9 & 29.6 & 11.1 & 33.3 & 100.0 \\
\hline Robo & 53.2 & 18.3 & 13.5 & 15.1 & 100.0 \\
\hline Secuestro & 72.7 & 18.2 & 0.0 & 9.1 & 100.0 \\
\hline Otro del fuero común & 36.8 & 13.2 & 23.7 & 26.3 & 100.0 \\
\hline Fuero federal & 74.8 & 9.3 & 3.3 & 12.6 & 100.0 \\
\hline Contra la salud & 76.4 & 8.8 & 3.2 & 11.6 & 100.0 \\
\hline Tráfico de indocumentados & 581.3 & 9.4 & 0.0 & 9.4 & 100.0 \\
\hline Otro del fuero federal & 50.0 & 13.6 & 9.1 & 27.3 & 100.0 \\
\hline \multicolumn{6}{|c|}{ B. Años de residencia por delitos } \\
\hline Total & 100.0 & 100.0 & 100.0 & 100.0 & 100.0 \\
\hline Fuero común & 32.2 & 62.1 & 75.0 & 53.3 & 43.1 \\
\hline Asalto & 0.7 & 4.5 & 2.5 & 1.3 & 1.4 \\
\hline Homicidio & 2.3 & 12.1 & 7.5 & 12.0 & 5.6 \\
\hline Robo & 22.0 & 34.8 & 42.5 & 25.3 & 26.0 \\
\hline Secuestro & 2.6 & 3.0 & 0.0 & 1.3 & 2.3 \\
\hline Otro del fuero común & 4.6 & 7.6 & 22.5 & 13.3 & 7.8 \\
\hline Fuero federal & 66.4 & 37.9 & 22.5 & 45.3 & 55.7 \\
\hline Contra la salud & 54.3 & 28.8 & 17.5 & 33.3 & 44.5 \\
\hline Tráfico de indocumentados & 8.6 & 4.5 & 0.0 & 4.0 & 6.6 \\
\hline Otro del fuero federal & 3.6 & 4.5 & 5.0 & 8.0 & 4.5 \\
\hline
\end{tabular}

FuENTE: Resultados del proyecto "Factores de riesgo asociados a enfermedades de transmisión sexual y por sangre en un cereso". Instituto de Investigaciones Sociales de la UABC, 2000-2001.

y los procedentes deotro estado del país, pues mientras que entre los primeros la proporción se el eva a 7.5 de cada diez internos, en los no nativos es de 4.9 por cada diez, es decir, es mucho más común que los internos nativos tengan adicción por las drogas que los no nativos.

Del total de internos que declararon consumir drogas, la frecuencia más al ta se registró en el consumo de mariguana (53.2\%), seguida por la heroína (45.6\%) y el cristal (42.7\%). Cabe destacar, 
CUADRO 8. Internos con más de un año en el cereso según tiempo en el penal, delitos cometidos y porcentaje de sentenciados a diciembre de 2000.*

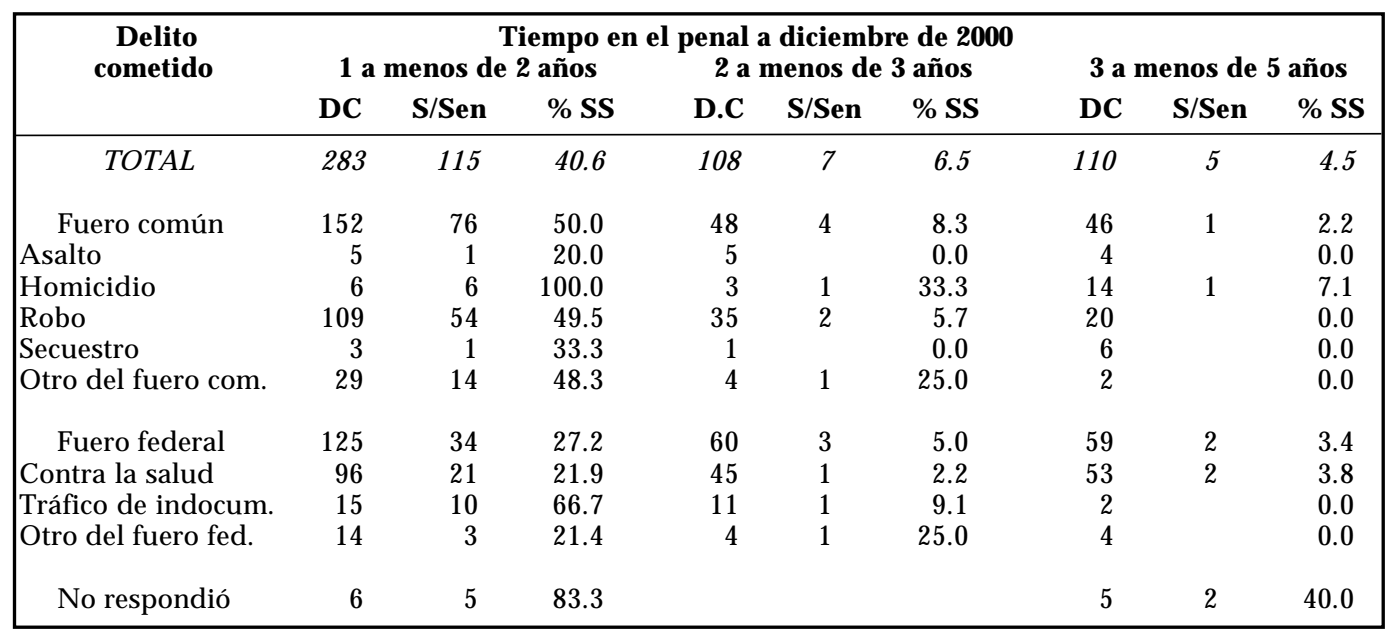

* Sólo incluye a los 283 internos que declararon su fecha de ingreso al cereso. Existen otros 100 internos que no declararon fecha de ingreso, de los cuales 36 no declararon el tiempo de su sentencia, y 18 dijeron no estar sentenciados o aún no saber su sentencia.

Com $=$ delitos cometidos

$\mathrm{S} / \mathrm{Sen}=$ sin sentencia

$\%$ SS = porcentaje de no sentenciados en relación con el total de delitos cometidos

FuENTE: Resultados del proyecto "Factores de riesgo asociados a enfermedades de transmisión sexual y por sangre en un cereso". Instituto de Investigaciones Sociales de la UABC, 2000-2001. 
Estudios Fronterizos, Nueva época, vol. 4, núm. 7, enero-junio de 2003

sin embargo, que la vida en el cereso incrementa las adicciones, pues $40.3 \%$ de los internos entrevistados ingresaron al reclusorio siendo ya adictos, mientras que el porcentaje de los que actualmente consumen algún tipo de droga es de 60.6\%; es decir, se incrementó 20\% (ver cuadro 9). Lo anterior implica que una tercera parte del total de los internos adictos adquirieron el hábito en el cereso.

Tres situaciones Ilaman la atención en la información del cuadro 9. La primera es que el delito que presenta el porcentaje más alto de reclusos que ingresaron con adicción es el robo (más dela mitad deellos), lo que parece confirmar la asociación entre robo y drogadicción; además, también es el delito que presenta la mayor frecuencia en consumo de drogas al momento del levantamiento de información (tres de cada cuatro). La segunda es que los delitos federales presentan un menor porcentaje de internos con adicciones, tanto al ingreso al penal como al momento del levantamiento. Y la tercera es que los internos tanto por tráfico de indocumentados como por delitos contra la sal ud (tráfico de drogas), son los que presentan las frecuencias más bajas en consumo, así como también los porcentajes más bajos de adquisición de hábito en el cereso, lo que hace evidente que la transportación o la distribución de drogas no necesariamente están asociadas a su consumo, sino a los beneficios económicos que proporciona (ver cuadro 9).

\section{UNA REFLEXIÓN FINAL}

La situación del Cereso de Mexicali aquí descrita muestra muchos de los problemas que en general presentan los centros penitenciarios del país, particularmente los referentes a instal aciones inadecuadas, estructuras de poder entre los internos y estratificación entre ellos; otros son reflejo de las características propias de la dinámica social dela región, a saber: una sociedad con un fuerte componente de inmigrantes, que ha sido permeada por actividades rel acionadas con el tráfico dedrogas, no sól o en la esfera de la distribución, sino también en el consumo, y un reducido sector 
CUADRO 9. Consumo de drogas por parte de los internos.*

\begin{tabular}{|lccc|}
\hline \multicolumn{1}{|c}{ D elito } & $\begin{array}{c}\text { Ingresaron } \\
\text { c/adicción }\end{array}$ & $\begin{array}{c}\text { Consumen } \\
\text { actualmente }\end{array}$ & $\begin{array}{c}\text { Incremento } \\
\text { en cereso }\end{array}$ \\
\hline \multicolumn{1}{|c}{ Total } & 40.3 & 60.6 & 20.3 \\
Fuero común & 44.7 & 70.4 & 25.7 \\
A salto & 45.5 & 72.7 & 27.3 \\
Homicidio & 21.4 & 64.3 & 42.9 \\
Robo & 51.2 & 75.7 & 24.6 \\
Secuestro & 25.0 & 62.5 & 37.5 \\
Otro del fuero común & 37.2 & 52.6 & 15.4 \\
Fuero federal & 34.5 & 48.0 & 13.5 \\
Contra la salud & 33.1 & 45.5 & 12.4 \\
Tráfico de indocum. & 28.2 & 41.0 & 12.8 \\
Otro del fuero federal & 52.6 & 76.3 & 23.7 \\
No respondió & 44.4 & 61.1 & 16.7 \\
\hline
\end{tabular}

* Porcentaje en relación con el total de internos (928 entrevistados).

FuENTE: Resultados del proyecto "Factores de riesgo asociados a enfermedades de transmisión sexual y por sangre en un cereso". Instituto de Investigaciones Sociales de la UABC, 2000-2001.

dedicado al tráfico deindocumentados, conocidos como "po-lleros", quienes internan personas ilegal mentea territorio estadounidense, actividad por demás lucrativa.

La población penitenciaria, al menos la entrevistada, se caracteriza por ser muy joven, particularmente los internos nacidos en Baja Cal ifornia. Esta diferencia deedades entrenativos y migrantes puede estar influida por la edad a la que llegan a la entidad los migrantes, generalmente mayores de edad. Además, estos últimos están sobrerrepresentados en el reclusorio, ya que más de la mitad son no nativos, porcentaje muy por arriba del observado en el total dela población a nivel municipal.

También resal ta el hecho de que se trata de una población con cierta educación, pues al menos tres cuartas partes reportan haber cursado educación básica; de hecho, el porcentaje de internos sin instrucción es inferior al promedio estatal, de aquí que no se observe una asociación entre escasa o nula educación con la de lincuencia. 
La ubicación fronteriza de M exicali sehaceevidenteen la comisión de delitos. Así, se observa que los delitos contra la salud (asociados al narcotráfico) son los más frecuentes, y la proporción de internos por cometer delitos federales, si bien no son la mayoría, sí tienen un peso relativo superior que el observado a nivel nacional y, en materia de delitos del fuero federal, el segundo lugar lo ocupa el de tráfico de personas.

Un indicador del efecto que en la sociedad mexical ensetieneel consumo de drogas es el hecho de que más de la mitad de los internos por robo ya eran consumidores de algún tipo de droga antes desu ingreso al reclusorio, y más de la mitad de los internos por este delito son originarios de Baja Cal ifornia. Este del ito ocupa el segundo lugar en importancia por su frecuencia y el primero en los del fuero común. Además, entre ellos se observa el incremento más fuerte en el consumo de drogas dentro del cereso.

Otro indicador dela mayor propensión al consumo de drogas por parte de los reclusos nativos es que, en total, seis de cada diez internos consume drogas, mientras que en los originarios de Baja Cal ifornia la razón se eleva a casi ocho de cada diez. La más comúnmenteconsumida es la mariguana, seguida por otras queson altamente adictivas o riesgosas en términos de posi bles contagios (heroína y cristal). Es también un hecho que la vida en el cereso promueveel consumo de estupefacientes, puesto que una tercera parte del total delos internos adictos adquirieron el hábito dentro del penal.

Los datos presentados, más que respuestas, plantean preguntas e hipótesis acerca de las cuales indagar, puesto que se observan ciertas diferencias en los patrones delictivos entre nativos y migrantes. En términos relativos, el peso de los migrantes en relación con los nativos es mucho mayor en la comisión de delitos del fuero federal, particularmente contra la salud y contra la ley de población (tráfico de indocumentados), mientras que los nativos son mayoría en casi todos los del itos del fuero común, con excepción del secuestro.

La pregunta deporquése da esta cierta especial ización plantea muchas posibles respuestas, quizá asociadas a la fal ta de empleo 
y a la necesidad de al legarse recursos ya sea para vivir (que puede ser el caso dealgunos migrantes) o para poder adquirir droga (que puede ser el caso de buena parte de los nativos internos por robo). No obstante, cabe advertir que, a pesar de los indicadores aquí presentados, es aventurado adelantar conclusiones en torno a la asociación de la migración con la delincuencia, en particular con la comisión de delitos del fuero federal, puesto quelos hallazgos aquí reportados también pueden ser manifestación de la ausencia o la debilidad de redes sociales de apoyo de los migrantes, las cuales pueden impedir el arresto en el caso de los nativos, es decir, es posible que los inmigrantes sean más propensos a ser capturados por las autoridades por el solo hecho de no haber nacido en Baja California.

Conocer el porquéo verificar las posibles respuestas mencionadas requiere conocer la historia de los internos - al menos de los que comparten un mismo tipo de delito-, investigación que va mucho más allá de los objetivos planteados en la investigación de la cual se obtuvieron los datos para la realización de este trabajo.

\section{ReferenCIAS BIBLIOGRÁfICAS}

Alegre, Luis. 2002. "Reubican a mil 988 reos en BC", R eforma, 20 de agosto.

A mericas Watch. 1991. D erechos humanos en M éxico. ¿U na política de impunidad?, Editorial Planeta, México.

Barreda Solórzano, Luis. 1991. “Propuesta y reporte sobreel sistema penitenciario mexicano", Comisión Nacional de Derechos Humanos, México.

Constitución Política delos Estados U nidos M exicanos 2002. Ediciones Delma, México.

Cornejo, Jorge A lberto. 2002. "Ya hay síndrome de abstinencia en EI Pueblito", La J ornada, 23 de agosto, México.

Huacuja Betancout, Sergio.1989. La desaparición de la prisión preventiva, Editorial Trillas, México.

INEGI. 2000. A nuario deestadísticas por entidad federativa, edición 2000, Aguascalientes. 
2001a. A nuario estadístico. Estados U nidos M exicanos, edición 2000, Aguascalientes.

2001b. XII Censo General de Población y V ivienda 2000. Tabulados Básicos, (Resumen Nacional y Baja California), Aguascalientes.

Jiménez Vega, Jesús. 2002. “Las cárceles de Baja California están sobrepobladas", La V oz de la Frontera, 22 de abril, Mexicali, B.C.

Programa de Prevención y Readaptación Social 1995-2000, 1996. Diario O ficial de la Federación, 19 de julio (Secretaría de Gobernación).

Secretaría de Gobernación.1998. «Reporte interno de la Dirección General dePrevención y Readaptación Social» (mimeo).

Zaffaroni, Eugenio Raúl. 1999. En busca de las penas perdidas. D eslegitimación y dogma jurídico-penal, Editorial Temis, Bogotá. 